\title{
High-Risk HPV DNA Test for Screening Anal Lesions in HIV-Positive and Negative Patients
}

Sylvia HeloisaArantes $\mathrm{Cruz}^{1}$ and Cristiano Ricardo Siqueira De Souza ${ }^{2}$

${ }^{1}$ Faculdade De Ciências Médicas Da Santa Casa De São Paulo, Sao Paulo - Sp - Brazil

${ }^{2}$ School of Economics, Business and Accounting, University Of São Paulo, São Paulo - Sp - Brazil

*Corresponding author: Sylvia Heloisa Arantes Cruz, Faculdade De Ciências Médicas Da Santa Casa De São Paulo, RuaMartinico Prado 26 cj 111,01224010 São Paulo Brazil, Tel +551133372558; E-mail: sylviahacruz@hotmail.com

Copyright: ( 2014 Cruz SHA, et al. This is an open-access article distributed under the terms of the Creative Commons Attribution License, which permits unrestricted use, distribution, and reproduction in any medium, provided the original author and source are credited.

Received date: April 21, 2014; Accepted date: May 26, 2014; Published date: June 10, 2014

\begin{abstract}
The high incidence of anal dysplasia is related to many factors. The infections caused by HPV and HIV seem to be determinants of the following anal Pap smear changes: atypical squamous cells of undetermined significance (ASCUS), low-grade anal intraepithelial neoplasia (LAIN) and high-grade anal intraepithelial neoplasia (HAIN). Highrisk HPV infection is confirmed by the HPV DNA test, using hybrid capture technology. Screening for anal lesions should be complemented with the anal Pap smear protocol and high-resolution anoscopy. The aim of this study was to evaluate the influence of the high-risk HPV DNA test on screening for anal lesions. We evaluated 70 HIV-positive and negative patients who had previously had anal intercourse, at CRT/AIDS São Paulo from January 2013 to December 2013. All of the patients underwent the high-risk HPV DNA test, anal Pap smear protocol and highresolution anoscopy. The anal lesions were treated with 90\% trichloroacetic acid (TCA) and 5\% imiquimod for 12 weeks. The statistical analysis was performed using hypothesis tests on proportions and the significance level was set at less than 5\%. 31 HIV-positive male patients, 19 HIV-negative male patients and $20 \mathrm{HIV}$-negative female patients were evaluated. 28 HIV-positive patients were positive for the high-risk HPV DNA test and 29 patients were positive for the high-risk HPV DNA test and had anal dysplasia. Our conclusion is that it was more common for HIVpositive patients to be infected with oncogenic HPV and the oncogenic HPV was more frequent in patients with anal dysplasia.
\end{abstract}

Keywords: Dysplasia; Acquired Immunodeficiency Syndrome; Anal canal; HIV; Human papillomavirus

\section{Introduction}

The high incidence of anal dysplasia is related to many factors. This dysplasia is described as high-grade anal intraepithelial neoplasia (HAIN), low-grade anal intraepithelial neoplasia (LAIN) or atypical squamous cells of undetermined significance (ASCUS). The factors that are important in such cases include epidemic infection caused by the human immunodeficiency virus (HIV), conditions of low systemic immunity, long use of highly active antiretroviral therapy (HAART), coexistence with preceding anal intercourse (i.e. among men who have with men, MSM) and infection caused by the high-risk human papillomavirus (HPV) [1,2].

Presence of anal carcinoma is linked with high-risk HPV infection, as is seen in cases of cervical, vaginal, vulvar and penile cancer [3]. HIV infection has changed the epidemiological profile of anal squamous cell carcinoma (ASCC), and the rate is at least twice as high in HIV-positive as in HIV-negative individuals [3,4]. Previously, ASCC was evident in elderly female patients, whereas nowadays young male patients with this cancer are seen [5]. ASCC is now considered to be directly related to sexually transmitted disease, since it has been shown to have a close relationship with HPV infection [6].

The prevalence of anal dysplasia in transplant patients has been increasing, thus showing a rise in the risk of anal cancer. A study on MSM who were renal transplant patients found that $20 \%$ had AIN and 47\% had high-risk HPV infection [7].
The screening procedures for anal dysplasia include anal Pap smears and high-resolution anoscopy [8]. High-risk HPV infection is confirmed by means of the HPV DNA test, using hybrid capture technology [9]. All of these tests seem to be effective in screening for anal dysplasia and anal cancer [10]. Recent studies have suggested that screening programs are cost-effective among the population that has previously had anal intercourse $[10,11]$.

An Australian meta-analysis has suggested that anal HPV and cancer precursors are common among MSM. However, it was found that the progression to cancer was lower than it was for cervical precancer lesions. There was no HAIN regression and most of the HIVpositive patients were recruited from clinics, while the HIV-negative patients were recruited from the community. The same study suggested that further prospective studies should be conducted inorder to develop anal cancer guidelines for patients with previous anal intercourse, with biomarkers to establish which patients would be at higher risk of progression to anal cancer and which would be likely to regress [12].

The aim of the present study was to evaluate the influence of highrisk HPV DNA test on screening for anal lesions [13].

\section{Material and Method}

This study was a cross-sectional descriptive case detection investigation, conducted in two study groups: HIV-positive and HIVnegative patients. We evaluated $70 \mathrm{HIV}$-positive and HIV-negative outpatients who had previously had anal intercourse, at CRT/AIDS São Paulo, in Brazil, from January 2013 to December 2013. The study 
Page 2 of 4

was approved by the Research Ethics Board of CRT/AIDS São Paulo. All of these patients had been referred to undergo the anal lesion screening protocol, by infectologists. These patients had previously had anal intercourse and were either HIV-positive or HIV-negative. The HIV-positive patients were receiving HAART.

The screening consisted firstly of a general clinical evaluation.This was followed by an anal Pap smear, a hybrid capture high-risk HPV DNA test and high-resolution anoscopy. The anal Pap smear was collected from the anal canal using a cytobrush: the swab was rotated in a cone-shaped arc against the anal canal for 30 seconds and the resultant material was smeared onto a glass slide and immediately fixed in ethanol for cytological evaluation [14,15]. The specimens were analyzed by a pathologist and reviewed by a senior pathologist. They were classified as normal, atypical squamous cells of undetermined significance (ASCUS), LAIN or HAIN [16].

The high-risk HPV DNA test was performed using a Dacron ${ }^{\circledR}$ swab at an insertion distance of $3 \mathrm{~cm}$, blindly into the anorectal canal. The swab was moved in and out for 15 seconds while rotating to sample all sides of the anal canal. The swab was then immersed in PreservCyt ${ }^{\circ}$ liquid-based cytological solution. The test uses probes for 13 types of oncogenic HPV: 16, 18, 31, 33, 35, 39, 45, 51, 52, 56, 58, 59 and 68. Specimens are positive for HPV if the target signal is greater than one [9].

High-resolution anoscopy was performed after topical application of $3 \%$ acetic acid in the anal canal for 2 minutes. The presence of lesions and their locations in the anal canal, tinctorial characteristics, appearance, surface characteristics and vascular profile were observed in accordance with a modified version of the Barcelona classification (2002) [17].

The patients presenting anal warts that were identified during the anoscopy were treated with $90 \%$ trichloroacetic acid (TCA) and 5\% imiquimod for 12 weeks [18].

All of the results were analyzed using hypothesis tests on proportions and the significance level was set at less than 5\% [19].

\section{Results}

20 women and 50 men were evaluated. The mean age of the women was 39.7 years and the mean age of the men was 34.3 years. All of the women were HIV-negative, 19men were HIV-negative and 31 men were HIV-positive.

13 women were found to have anal warts during high-resolution anoscopy, 4 showed LAIN and 3 showed ASCUS. 11 womenwere positive in the high-risk HPV DNA test. The women with anal warts were treated with $90 \%$ TCA and 5\% imiquimod. There were no residual lesions after this treatment.

7 HIV-negative men were found to have anal warts during highresolution anoscopy, 1 showed LAIN and 8 showed ASCUS. 16 HIVnegative men were positive in the high-risk HPV DNA test. These patients with anal warts were treated with 90\% TCA and 5\% imiquimod. There were no residual lesions after this treatment.

The average CD4 T lymphocyte count was 574 and the viral load was undetectable in the HIV-positive group. $12 \mathrm{HIV}$-positive men were found to have anal warts during high-resolution anoscopy, 7 showed LAIN and 9 showed ASCUS. 28 HIV-positive men were positive in the high-risk HPV DNA test. These patients with anal warts were treated with $90 \%$ TCA and 5\% imiquimod. There were no residual lesions after this treatment.These patients were subsequently reevaluated every six months.

We did not identify any cases of HAIN or ASCC.

The HIV-positive group was quite similar to the HIV-negative group, since the viral load was low and the CD4 T lymphocyte count was high.

We conducted a series of proportion tests using several hypotheses. First, we tested the relationships between the high-risk HPV DNA test and the presence of anal warts, but found no difference between the groups $(\mathrm{p}=0.4667)$. These outcomes are presented in Table 1.

\begin{tabular}{|l|l|l|}
\hline & HPV - & HPV+ \\
\hline Presence of anal warts & 7 & 25 \\
\hline Total patients & 15 & 55 \\
\hline Proportion of anal warts & $47 \%$ & $45 \%$ \\
\hline p-value of test & 0.4667 & \\
\hline
\end{tabular}

Table 1: High-risk HPV DNA test and anal warts in HIV-positive and negative patients.

Next, we compared the presence of anal warts in the HIV-positive group and the HIV-negative group. We did not reject the null hypothesis of no difference between the groups ( $\mathrm{p}=0.1471$ ). The results from the estimates are presented in Table 2.

\begin{tabular}{|l|l|l|}
\hline & HIV- & HIV+ \\
\hline Presence of anal warts & 20 & 12 \\
\hline Total patients & 39 & 31 \\
\hline Proportion of anal warts & $51 \%$ & $39 \%$ \\
\hline p-value of test & 0.1471 & \\
\hline
\end{tabular}

Table 2: Presence of anal warts in HIV-positive and negative patents.

Subsequently, we analyzed the relationship between the high-risk HPV DNA test and HIV-positive and negative patients. This showed that high-risk HPV DNA was more common in the HIV-positive group than in the negative one $(\mathrm{p}=0.0163)$. These results are showed on Table 3.

\begin{tabular}{|l|l|l|}
\hline & HIV- & HIV+ \\
\hline HPV & 27 & 28 \\
\hline Total patients & 39 & 31 \\
\hline Proportion of HPV & $69 \%$ & $90 \%$ \\
\hline p-value of test & 0.0163 & \\
\hline
\end{tabular}

Table 3: Presence of high-risk HPV in HIV-positive and negative patients.

Finally we analyzed the relationship between a positive high-risk HPV DNA test result and the anal Pap-smear findings. This showed that high-risk HPV test was more common in the patients in which 
the anal Papsmear was correlated with dysplasia $(\mathrm{p}=0.0121)$. These outcomes are presented in Table 4.

\begin{tabular}{|l|l|l|}
\hline & HPV- & HPV+ \\
\hline Anal dysplasia & 3 & 29 \\
\hline Total patients & 15 & 55 \\
\hline Proportion of anal dysplasia & $20 \%$ & $53 \%$ \\
\hline p-value of test & 0.0121 & \\
\hline
\end{tabular}

Table 4: Presence of high-risk HPV in relation to anal dysplasia findings.

\section{Discussion}

It was shown that high-risk HPV infection was more common in HIV-positive patients. This finding merits discussion because, even with high CD4 T lymphocyte counts, high-risk HPV is commonly reported [20]. We found in a previous study that a low CD4 T lymphocyte count was an important factor relating to appearance of anal warts and dysplasia in HIV-positive patients [2].

The incidence of anal cancer in MSM is very high,even after HAART. There are high rates of HPV infections and HPV lesions. This reflects the growing HIV epidemic and increasing longevity of HIV-positive individuals. Screening with anal cytological tests could benefit patients who are at higher risk of developingASCC.Patients with LAIN and HAIN found through anal Pap smears should be submitted to biopsies to confirm the anal dysplasia [21]

Anal Pap-smear tests are commonly offered to patients who are at higher risk of anal cancer. However, high-resolution anoscopy provides additional evaluation even for patients with negative Pap smears [22,23].

Papaconstantinou et al. found that anal cytological tests alone were not accurate for detecting anal dysplasia in patients with anal warts. Positive cytological tests need to be further investigated with biopsies. A positive high-risk HPV test could identify low-risk lesions that have greater potential for progression to advanced disease. The test increases the sensitivity of anal cytological screening [24].

Use of $5 \%$ imiquimod for 12 to 16 weeks had regressive action on anal dysplasia, decreased the recurrence rate after treatment and had anti-HPV action. Our data showed better results from treatments using $5 \%$ imiquimod than has been reported in the literature: previous data showed that the expected clinical response would be around $48 \%$ [25].

Our data showed that positive results from the high-risk HPV test were more common among the patients for whom the anal Pap-smear findings were correlated with dysplasia. A positive high-risk HPV test could reduce the number of patients that require high-resolution anoscopy if ASCUS was the only finding from the anal Pap smear [26]. However, high-resolution anoscopy provides additional evaluation, even for patients with negative Pap smears. The finding of HPV in the anus might indicate that the perineum could be exposed as well [27].

In another study, samples collected using Dacron ${ }^{\circledR}$ swabs for hybrid capture had higher relative unit values and more frequently identified HPV-positive patients than did samples collected using a cervical brush. Therefore, this was our choice for screening patients [13]. All of these findings suggest that HPV infection is important for the development of LAIN, HAIN and ASCUS, and that HIV-positivity increases the risk of disease in HPV-positive subjects [27]. Today, the high-risk HPV DNA test would be helpful for screening patients with anal dysplasia [21].

\section{Conclusion}

Our conclusion is that it was more common for HIV-positive patients to be infected by oncogenic HPV and the oncogenic HPV was more frequent in patients with anal dysplasia.

\section{Acknowledgements}

\section{References}

1. Arain S, Walts AE, Thomas P, Bose S (2005) The Anal Pap Smear: Cytomorphology of squamous intraepithelial lesions. Cytojournal 2: 4.

2. Cruz SHA, Souza CRS (2013) Screening-Related Factors in Anal Canal Lesions in HIV-Positive Patients. J AIDS Clin Res 4: 243.

3. Wilkin TJ, Palmer S, Brudney KF, Chiasson MA, Wright TC (2004) Anal intraepithelial neoplasia in heterosexual and homosexual HIV-positive men with access to antiretroviral therapy. J Infect Dis 190: 1685-1691.

4. Cruz SH, Nadal SR, Nadal CR, Calore EE (2012) Evaluation of Langerhans cells counts comparing HIV-positive and negative anal squamous cell-carcinoma patients. Acta Cir Bras 27: 720-726.

5. Gervaz P, Calmy A, Durmishi Y, Allal AS, Morel P (2011) Squamous cell carcinoma of the anus-an opportunistic cancer in HIV-positive male homosexuals. World J Gastroenterol 17: 2987-2991.

6. Nadal SR, Cruz SHA (2009) Seguimento dos doentessoropositivos e soronegativospara o HIV com carcinoma espinocelular anal. Rev Bras Coloproct 29: 404-407.

7. Patel HS, Silver AR, Northover JM (2007) Anal cancer in renal transplant patients. Int J Colorectal Dis 22: 1-5.

8. Gimenez F, Costa-e-Silva IT, Daumas A, AraújoJd, Medeiros SG, et al. (2011) The value of high-resolution anoscopy in the diagnosis of anal cancer precursor lesions in HIV-positive patients. ArqGastroenterol 48: 136-145.

9. Goldstone SE, Lowe B, Rothmann T, Nazarenko I (2012) Evaluation of the hybrid capture 2 assay for detecting anal high-grade dysplasia. Int J Cancer 131: 1641-1648.

10. Goldstone SE, Moshier E (2010) Detection of oncogenic human papillomavirus impacts anal screening guidelines in men who have sex with men. Dis Colon Rectum 53: 1135-1142.

11. Lam JM, Hoch JS, Tinmouth J, Sano M, Raboud J, et al. (2011) Costeffectiveness of screening for anal precancers in HIV-positive men. AIDS 25: 635-642.

12. Machalek DA, Poynten M, Jin F, Fairley CK, Farnsworth A, et al. (2012) Anal human papillomavirus infection and associated neoplastic lesions in men who have sex with men: a systematic review and meta-analysis. Lancet Oncol 13: 487-500.

13. Roka F, Roka J, Trost A, Schalk H, Zagler C, et al. (2008) Anal human papillomavirus testing with Digene's hybrid capture 2 using two different sampling methods. Dis Colon Rectum 51: 62-66.

14. Weis SE, Vecino I, Pogoda JM, Susa JS, Nevoit J, et al. (2011) Prevalence of anal intraepithelial neoplasia defined by anal cytology screening and high-resolution anoscopy in a primary care population of HIV-infected men and women. Dis Colon Rectum 54: 433-441.

15. Moscicki AB, Hills NK, Shiboski S, Darragh TM, Jay N, et al. (1999) Risk factors for abnormal anal cytology in young heterosexual women. Cancer Epidemiol Biomarkers Prev 8: 173-178.

16. Bakotic WL, Willis D, Birdsong G, Tadros TS (2005) Anal cytology in an HIV-positive population: a retrospective analysis. ActaCytol 49: 163-168.

17. Walker P, Dexeus S, De Palo G, Barrasso R, Campion M, et al. (2003) International terminology of colposcopy: an updated report from the 
Citation: Cruz SHA, De Souza CRS (2014) High-Risk HPV DNA Test for Screening Anal Lesions in HIV-Positive and Negative Patients. J AIDS Clin Res 5: 316. doi:10.4172/2155-6113.1000316

Page 4 of 4

International Federation for Cervical Pathology and Colposcopy. ObstetGynecol 101: 175-177.

18. Fox PA, Nathan M, Francis N, Singh N, Weir J, et al. (2010) A doubleblind, randomized controlled trial of the use of imiquimod cream for the treatment of anal canal high-grade anal intraepithelial neoplasia in HIVpositive MSM on HAART, with long-term follow-up data including the use of open-label imiquimod. AIDS 24: 2331-2335.

19. Kirkwood BR, Sterne JAC (2003) Essential Medical Statistics. (2nd Edn.) Blackwell Publishing.

20. Anderson J, Hoy J, Hillman R, Gittleson C, Hartel G, et al. (2008) Abnormal anal cytology in high-risk human papilloma virus infection in HIV-infected Australians. Sex Transm Infect 84: 94-96.

21. Walts AE, Thomas P, Bose S (2005) Anal cytology: is there a role for reflex HPV DNA testing? DiagnCytopathol 33: 152-156.

22. Lee EQ, Goldstone SE (2011) Predictors of anal dysplasia in men who have sex with men with benign cytology. Dis Colon Rectum 54: 347-351.
23. Darragh TM, Winkler B (2011) Anal cancer and cervical cancer screening: key differences. Cancer Cytopathol 119: 5-19.

24. Papaconstantinou HT, Lee AJ, Simmang CL, Ashfaq R, Gokaslan ST, et al. (2005) Screening methods for high-grade dysplasia in patients with anal condyloma. J Surg Res 127: 8-13.

25. Steele SR, Varma MG, Melton GB, Ross HM, Rafferty JF, et al. (2012) Practice parameters for anal squamous neoplasms. Dis Colon Rectum 55: 735-749.

26. Goldstone SE, Kawalek AZ, Goldstone RN, Goldstone AB (2008) Hybrid Capture II detection of oncogenic human papillomavirus: a useful tool when evaluating men who have sex with men with atypical squamous cells of undetermined significance on anal cytology. Dis Colon Rectum 51: 1130-1136.

27. Melbye M, Smith E, Wohlfahrt J, Osterlind A, Orholm M, et al. (1996) Anal and cervical abnormality in women--prediction by human papillomavirus tests. Int J Cancer 68: 559-564. 